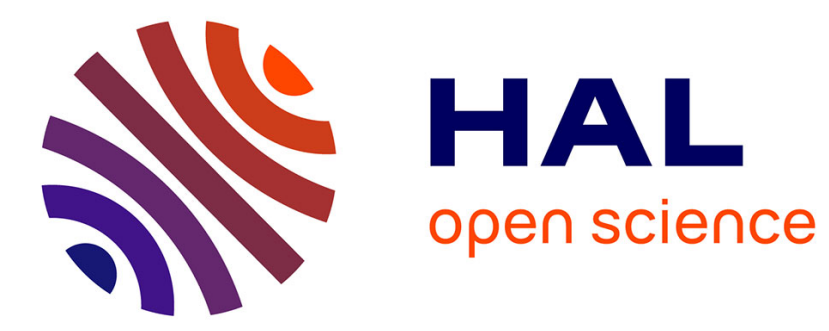

\title{
HEAVY ION SECONDARY BEAMS
}

R. Bimbot, S. Della-Negra, M. Manasijevic, P. Aguer, G. Bastin, R. Anne, H.

Delagrange, Y. Schutz, F. Hubert, Y. Gono, et al.

\section{To cite this version:}

R. Bimbot, S. Della-Negra, M. Manasijevic, P. Aguer, G. Bastin, et al.. HEAVY ION SECONDARY BEAMS. International Conference on Heavy Ion Nuclear Collisions in the Fermi Energy Domain, 1986, Caen, France. pp.C4-241-C2-243, 10.1051/jphyscol:1986428 . jpa-00225794

\section{HAL Id: jpa-00225794 https://hal.science/jpa-00225794}

Submitted on 1 Jan 1986

HAL is a multi-disciplinary open access archive for the deposit and dissemination of scientific research documents, whether they are published or not. The documents may come from teaching and research institutions in France or abroad, or from public or private research centers.
L'archive ouverte pluridisciplinaire HAL, est destinée au dépôt et à la diffusion de documents scientifiques de niveau recherche, publiés ou non, émanant des établissements d'enseignement et de recherche français ou étrangers, des laboratoires publics ou privés. 


\section{HEAVY ION SECONDARY BEAMS}

R. BIMBOT, S. DELla-NEgRa, M. MANASIJEViC*, P. AGUeR* * ,

G. BASTIN $^{*}$, R. ANNE AN* $^{* *}$ H. DELAGRANGE ${ }^{* *}$, Y. SCHUTZ***,

F. HUBERT ${ }^{+}, Y$. GONO $^{++}$and K. HATANAKA ${ }^{+*}$

Institut de Physique Nucléaire, BP I, F-91406 orsay, France

* IPN, Orsay and Boris Kidric Institute, Belgrade, Yugoslavia

"* CSNSM, BP 1, F-91406 Orsay, France

* * GANIL, BP 5027, F-14021 Caen, France

+CENBG, Le Haut Vigneau, F-33170 Gradignan, France

++RIKEN, Wako-Shi, Saitama 351, Japan

Abstract : The possibility of producing secondary beams of radioactive nuclei is an interesting application of medium and high energy heavy ion beams. After a first attempt at CERN (1), two experiments have been performed at GANIL, using $44 \mathrm{MeV} / \mathrm{u} 40 \mathrm{Ar}$ (2) and $65 \mathrm{MeV} / \mathrm{u} 180$ projectiles. This paper recalls the results of the Ar experiment, and presents new data obtained with the 180 beam.

\section{EXPERIMENTAL TECHNIQUE}

The radioactive nuclei are produced in a thick target of a light element through projectile fragmentation or transfer. The products emitted at zero degree are separated from the primary beam using a magnetic spectrometer of large angle and energy acceptance (LISE). The secondary beam is transported over $18 \mathrm{~m}$ and refocused in a spot of diameter less than $15 \mathrm{~mm}$. The spectrometer is composed of two dipoles and 10 quadrupoles. It is described in ref. (3). Beam diagnostics make it possible to visualize the beam profiles in several points. A solid state detector telescope $(\triangle E, E)$ is placed at the achromatic focus in order to analyse the isotopic composition of the secondary beam. Details about the experimental procedure can be found in ref. (2).

\section{EXPERIMENTAL RESULTS}

\subsection{Ar_beam}

Secondary beams of masses around 40 and energies around $34 \mathrm{MeV} / \mathrm{u}$ have been produced using a $99 \mathrm{mg} / \mathrm{cm}^{2}$ Be target. The yields $\mathrm{I} / \mathrm{I}_{0}$ (secondary/primary beam intensity) obtained (2) for these beams are given in table 1.

\begin{tabular}{|c|c|c|c|c|c|c|c|}
\hline $\begin{array}{c}\text { Primary } \\
\text { beam }\end{array}$ & Target & S.B. & $\mathrm{I} / \mathrm{I}_{\mathrm{O}}$ & S.B. & $\mathrm{I} / \mathrm{I}_{0}$ & S.B. & $\mathrm{I} / \mathrm{I}_{0}$ \\
\hline & & 11 & $5-5$ & & & & \\
\hline $\begin{array}{l}44 \mathrm{MeV} / \mathrm{u} \\
40_{\mathrm{Ar}}\end{array}$ & $\begin{array}{l}99 \mathrm{mg} / \mathrm{cm}^{2} \\
\mathrm{Be}\end{array}$ & $4 I_{K}$ & $5.10^{-5}$ & $\begin{array}{l}38 \mathrm{Ar} \\
{ }^{39} \mathrm{Ar}\end{array}$ & $\begin{array}{r}10^{-4} \\
3.10^{-4}\end{array}$ & $\begin{array}{l}39 \mathrm{Cl} \\
38 \mathrm{~S}\end{array}$ & $\begin{array}{r}10^{-4} \\
0.6 \cdot 10^{-5}\end{array}$ \\
\hline $65 \mathrm{MeV} / \mathrm{u}$ & $567 \mathrm{mg} / \mathrm{cm}^{2}$ & $18_{N}$ & $2.10^{-6}$ & $16 \mathrm{C}$ & $2.10^{-6}$ & $13_{B}$ & $1.5 .10^{-6}$ \\
\hline 180 & $\mathrm{Be}$ & $17_{N}$ & $\sim 10^{-4}$ & $15 \mathrm{C}$ & $4.10^{-6}$ & $12 \mathrm{~B}$ & $10^{-6}$ \\
\hline & & $16_{N}$ & $\geq 10^{-4}$ & ${ }^{14} \mathrm{C}$ & $10^{-4}$ & $111_{B}$ & $\approx 5.10^{-6}$ \\
\hline $\begin{array}{l}65 \mathrm{MeV} / \mathrm{u} \\
18_{0}\end{array}$ & $\begin{array}{l}1026 \mathrm{mg} / \mathrm{cm}^{2} \\
\mathrm{Be}\end{array}$ & $17_{N}$ & $5.10^{-6}$ & ${ }^{16} \mathrm{C}$ & $0.5 .10^{-6}$ & & \\
\hline
\end{tabular}

Table 1 : Production yields (I/IO) for various secondary beams (S.B.) obtained from $40 \mathrm{Ar}$ and 180 primary beams. 


\subsection{0 beam}

\subsubsection{Production of $50 \mathrm{MeV} / \mathrm{u}$ secondary beams}

Using a $567 \mathrm{mg} / \mathrm{cm}^{2}$ Be target, various secondary beams of about $50 \mathrm{MeV} / \mathrm{u}$ have been produced in the mass range 10-18. An example of the beam profiles observed at the achromatic focus is given in fig. $1 \mathrm{a}$. The emittance of a ${ }^{16} \mathrm{C}$ secondary beam has been measured using the beam profiles in two different positions, and is equal to $30 \pm 6 \pi \mathrm{mm} . \mathrm{mrad}$.

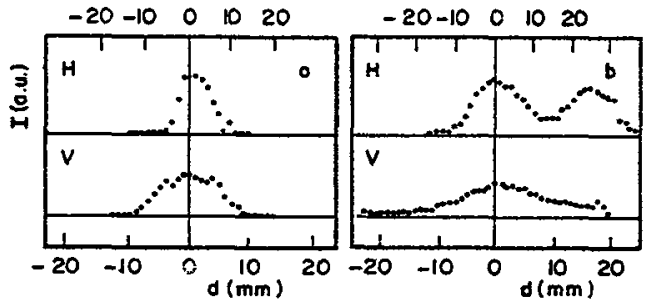

Fig. 1 : Horizontal (H) and vertical (V) beam profiles observed at the LISE achromatic focus. The intensity collected on each wire is plotted versus the wire position $d$. Note that the wire spacing is equal to $1 \mathrm{~mm}$ for vertical profiles and to $1.5 \mathrm{~mm}$ for the horizontal ones.

a. Non purified $16 \mathrm{C}$ beams produced in a $567 \mathrm{mg} / \mathrm{cm}^{2}$ or in a $1036 \mathrm{mg} / \mathrm{cm}^{2}$ Be target (similar profiles are observed for both targets).

b. Secondary beams produced in a 1036 $\mathrm{mg} / \mathrm{cm}^{2}$ Be target and purified with a $150 \mathrm{mg} / \mathrm{cm}^{2} \mathrm{Al}$ degrader. The horizontally centered peak contains almost pure $16 \mathrm{C}$, the peak on the right is a mixture of several components, the main ones being $15 \mathrm{C}$ and $13 \mathrm{~B}$.

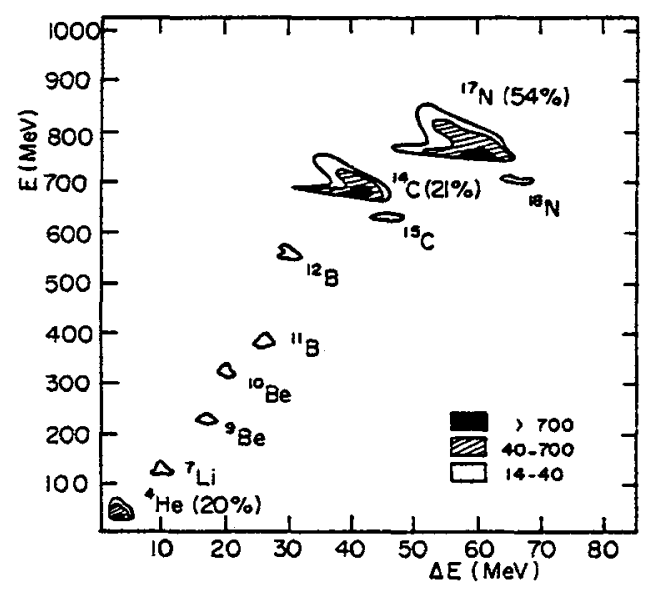

Fig. 2 : Bidimensional plot showing the isotopic composition of a secondary beam obtained in the following conditions : $65 \mathrm{MeV} / \mathrm{u} 180+567 \mathrm{mg} / \mathrm{cm}^{2} \mathrm{Be}$; $B \rho=2.44 \mathrm{Tm} ; \Delta B \rho / B \rho= \pm 0.17 \%$. The abundances of the main components are given in parenthesis.

The isotopic composition of a secondary beam optimized for $17 \mathrm{~N}$ production is shown in fig. 2. Such bidimensional plots, associated with primary beam intensity measurements are used to determine the production yield for each isotope, and for each value of the magnetic rigidity $B \rho$. The resulting curves are presented in fig. 3 , and the maximum production rates deduced from these curves, are given in table 1 . Note the relatively high yields for $16-17 \mathrm{~N}$ and $14 \mathrm{C}$, and also the odd even effects in the production of the couples $15 \mathrm{C}-16_{\mathrm{C}}$ and $12 \mathrm{~B}-13_{\mathrm{B}}$. The significant yield for $18_{\mathrm{N}}$ is interesting to remark, firstly because it is a relatively exotic nucleus, and secondly because it can be produced only through a transfer (charge exchange) reaction.

\subsubsection{Production and purification of $34 \mathrm{MeV} / \mathrm{u}$ secondary beams}

Secondary beams have been produced around $34 \mathrm{MeV} / \mathrm{u}$ from the $65 \mathrm{MeV} / \mathrm{u} 180$ beam using a $1036 \mathrm{mg} / \mathrm{cm}^{2}$ Be target. Due to the increase in target thickness, the $B \rho$ distribution for each isotope is now much broader. As a consequence, the individual yields for a given $B \rho$ value are lower than with the $567 \mathrm{mg} / \mathrm{cm}^{2}$ taraet (see table 1). The influence of the target nature was studied using $1138 \mathrm{mg} / \mathrm{cm}^{2} A \overline{1}$ and $1350 \mathrm{mg} / \mathrm{cm}^{2} \mathrm{Ni}$ targets which lead to the same energy for secondary beams. This study showed that Be targets are more efficient by a factor 2.5 relative to $\mathrm{Al}$ and 5 relative to $\mathrm{Ni}$ targets for the production of secondary beams of masses not very far from the projectile one. These numbers correspond to almost equivalent cross sections in the three targets. 


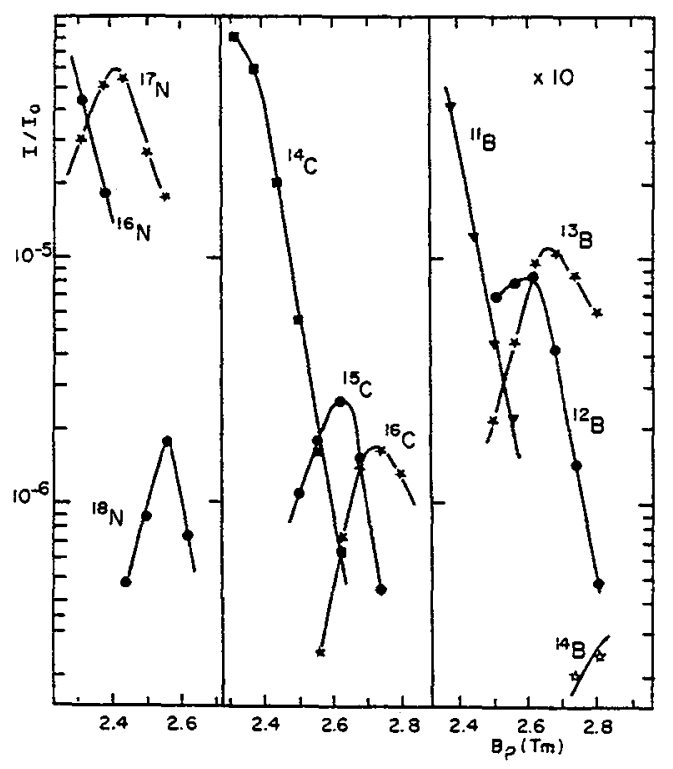

Fig. 3 : Variation of the production ratio I/1o of secondary beams with the magnetic rigidity $B \rho$, for a $B \rho$ acceptance of $\pm 1.67 \%$ $\left(65 \mathrm{MeV} 180+567 \mathrm{mg} / \mathrm{cm}^{2} \mathrm{Be}\right)$.

With such thick targets, a beam obtained for a given $B \rho$ value is now composed of a large number of nuclides, as can be seen in fig. 4a. An efficient purification can be performed by using a wedge degrader (achromatic) placed between the two dipoles. After going through this degrader, secondary beams are dispersed by the second dipole according to their new magnetic rigidity. This can be seen in fig. 16 where a beam profile obtained at the focus in these conditions is displayed. By setting the proper vaiue of the second dipole magnetic field, a spectacular purification of $16 \mathrm{C}$ is achieved, as shown in fig. 4b. This is made with negligible intensity loss for $16 \mathrm{C}$. Another tuning of dipole 2 selects a mixture of beams corresponding to the same magnetic rigidity after going through the degrader (see fig. 4c).

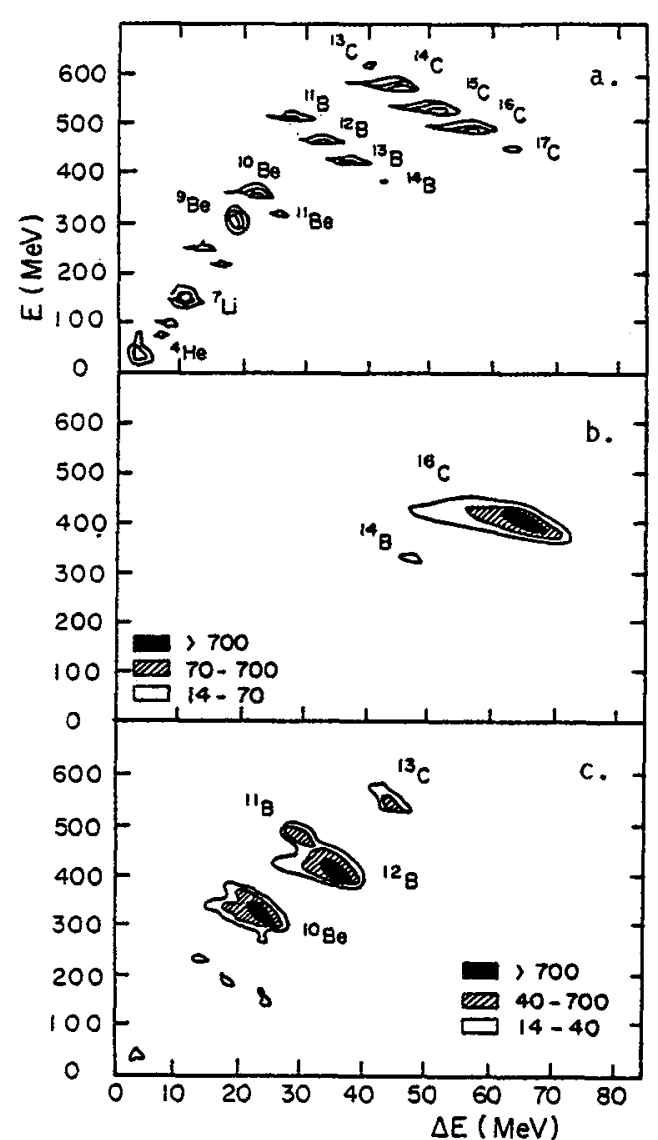

Fig. 4 : Same as fig. 2 for a 1036 $\overline{\mathrm{mg} / \mathrm{cm}^{2}}$ Be target

a. unpurified beam $\left(B_{\uparrow} \rho=2.248 \mathrm{Tm}\right.$, $\triangle \mathrm{B} \rho / \mathrm{B} \rho= \pm 0.22 \%)$

b. $16 \mathrm{C}$ purified beam (same $\mathrm{B}_{1} \rho, 150$ $\mathrm{mg} / \mathrm{cm}^{2} \mathrm{Al}$ intermediate degrader, $\mathrm{B}_{2} \rho=2.114 \mathrm{Tm}, \Delta \mathrm{B} \rho / \mathrm{B} \rho= \pm 2.78 \%$ )

c. secondary beam obtained with the same $B_{1} \rho$ and $\triangle B_{\rho} / B_{\rho} \rho$ values, and $B_{2 \rho}=2.154 \mathrm{Tm}$.

This study shows that the best purification of a given secondary beam can only be obtained by a careful selection of target thickness, magnetic field in first dipole, $B \rho$ acceptance, degrader thickness and magnetic field in second dipole.

\section{References}

1. A. Fleury et al, Nucl. Instr. and Meth. B10-11 (1985) 369

2. R. Bimbot et al, Z. Phys. A322 (1985) 443

3. R. Anne et C. Signarbieux, GANIL report RA/NJ 278-82 (1982) 